\title{
THE ECONOMICS OF VECTOR CONTROL STRATEGIES FOR CONTROLLING TROPICAL DISEASES
}

\author{
ANNE MILLS \\ London School of Hygiene and Tropical Medicine and London School of Economics and Political \\ Science, London, United Kingdom
}

\begin{abstract}
This paper describes the techniques of economic evaluation and how they can help improve the efficiency of vector control strategies for controlling tropical diseases. The differences among the techniques are clarified, and the main components of each analytical approach are presented, as well as some of the major problems in their application. The historic evolution of the application of economics to vector control in developing countries is summarized, before analyzing some more recent studies that have explored some of the choices concerning vector control. The paper concludes with some recommendations for improving the quality and, therefore, the usefulness of studies.
\end{abstract}

\section{THE UTILITY OF ECONOMICS}

The prime concern of the discipline of economics is with the implications of the scarcity of resources and the need to make choices on how best to use them. Given scarce resources, what criteria should public sector decision-makers use to judge whether a particular action is or is not worthwhile? The answer is straightforward, even if putting it into practice is not. An action is good or bad by reference to social objectives, and by reference to the action's costs (anything that detracts from social objectives) and its benefits (anything that contributes to social objectives).

This begs the question of what are the social objectives. The most obvious one is efficiency, since the greater the efficiency with which resources are used, the more it is possible to achieve with them. In particular, efficiency in resource use contributes to raising per capita income, a universal objective of tropical countries. Economic efficiency has two aspects: the first is operational efficiency, to produce a given output at minimum cost or maximize output for a given cost (the common sense notion of efficiency, which could be referred to as economy); the second is allocative efficiency, to produce the best or optimal combination of outputs (that which is socially desired) by means of the least cost combination of inputs.

Efficiency is not however the only objective governments seek to achieve. Equity, the distribution of national income between different groups in society, may also be an objective, as may others such as employment. In relation to health, raising health status overall and in relation to particular groups of the population may themselves be objectives in their own right.

During the past thirty years, economists have been increasingly concerned that whereas it is possible to define the conditions under which a private market will achieve efficiency, and the environment that will create the necessary incentives, such incentives are lacking in public bureaucracies. In particular, in the absence of the market, rules are needed to guide resource allocation decisions. Thus, since the 1950s, economists have been developing techniques that can be applied to public sector investment alternatives to help decide which projects will have the greatest net impact on social objectives and thus should be implemented. Early efforts concentrated on developing the technique of cost-benefit analysis, in which both costs and benefits are valued in monetary terms so that they can be directly compared.' This technique has been developed into a comprehensive system for appraisal of investment alternatives in developing countries, ${ }^{2}$ and can be used to analyze allocative efficiency.

Cost-benefit analysis is difficult to apply in the health sector (as discussed later) because of the problems of placing a value on benefits. Considerable effort has been put into developing alternative techniques, particularly that of costeffectiveness analysis, which takes the objective of health improvement as given and compares health effects with costs expressed in monetary terms. Since the objective is not questioned (and a value not placed on it), the technique is of greatest use in analyzing operational rather than 
allocative efficiency. In developed countries, cost-utility analysis has become popular. This involves weighting effects by a measure of their utility.

Cost-benefit analysis and cost-effectiveness analysis are frequently confused; moreover, there have been recent developments in the technique of cost-effectiveness analysis that bring it rather closer to cost-benefit analysis. Thus, it is important to be clear on the distinctions within the family of techniques. The following are the components included. ${ }^{3}$

Costs:

$C_{1}$-Direct costs (the direct resource costs of implementing an activity)

$\mathrm{C}_{2}$ - Indirect costs (loss of production associated with being involved in the activity, e.g., as a patient)

$\mathrm{C}_{3}$-Intangible costs (e.g., pain and anxiety caused by treatment).

\section{Outputs:}

E-Health effects (e.g., reduction in morbidity and mortality)

U-Utility weighted health effects (e.g., as measured by quality adjusted life years)

B-Associated economic benefits

$B_{1}$-Direct benefits (savings in treatment or prevention costs)

$B_{2}$-Indirect benefits (gain in production because of improved health, or directly because of project-related income-generating activities)

$B_{3}$-Intangible benefits (the value of health per se).

Cost analysis includes $C_{1}$ and sometimes $C_{2}$ as well. Cost-effectiveness analysis in its simplest form (the one most frequently found in developing country studies) divides $C_{1}$ (sometimes plus $C_{2}$ ) by $E$. However, studies in Europe and the United States now routinely subtract $B_{1}$ and $B_{2}$ from $C_{1}$ and $C_{2}$, producing net costs, before dividing by $\mathrm{E}$. Cost-utility analysis is calculated in the same way as cost-effectiveness analysis, except that $E$ is replaced by $U$. Cost-benefit analysis ideally subtracts all the $C$ components from all the B components; or divides the Bs by the Cs. However, no completely satisfactory means exists for putting a monetary value on $\mathbf{B}_{\mathbf{3}}$. Thus, most studies consider only $C_{1}$ and $C_{2}$, and $B_{1}$ and $B_{2}$. It can clearly be seen that in this form, cost-benefit analysis adds nothing to the more complex version of cost-effectiveness analysis.

The essence of economic analysis is the comparison of alternative courses of action. In theory, therefore, it is undesirable to restrict the scope of an analysis, once the nature of the health objective that the alternatives compared seek to achieve has been specified. For example, if the objective is to improve health, alternatives could range across the whole health sector. According to this approach, it makes little sense to consider vector control strategies separately from other strategies that may control vectorborne diseases, or from other interventions that may improve health. In practice, however, analytical feasibility and organizational realities limit to some extent the scope of the choices evaluated. Vector control activities are frequently organized by a single Ministry of Health department, which has some discretion to allocate resources both among different vector-borne diseases and to different vector control strategies. Moreover, a particular strategy may control several vector-borne diseases. Therefore, it is useful for vector control managers to see how economic analysis can be applied to the range of choices open to them. However, it should not be forgotten that there will be choices to be faced by higher level decision-makers concerning the allocation of resources when restricting the boundaries of the analysis to a particular subset of diseases and strategies would risk ignoring interventions that might improve health at less cost.

Before discussing the evolution of the application of economics to vector control strategies in developing countries, it is important to forewarn readers of some of the problems in measuring these components and doing the analyses. In relation to costs, cost data are rarely produced by project accounts: even if project accounts are available, they may be out of date and inaccurate. Shaw provides a useful comment on the deficiencies of project accounts in relation to determining costs for human trypanosomiasis control, ${ }^{4}$ suggesting that project accounts should routinely distinguish categories such as variable costs and overhead costs. Another common problem is that some resources are inputs to 
more than one activity, i.e., costs are joint. This can provide a particular problem for vector control evaluations where vector control is part of a water resource development project. ${ }^{5}$ For example, Tameim and others were faced with the problem of deciding what share of water supply costs should be attributed to schistosomiasis control in an irrigation scheme in Sudan. ${ }^{6}$ Onethird was allocated to control and the other twothirds to diarrheal diseases and labor savings, but without a clear justification. A final concern about many cost studies is that costs falling on households and communities are omitted, raising the possibility that an option may be chosen that minimizes costs to the government, but has higher social costs than another option because it imposes costs on households.

In relation to effects, the major problem is that of predicting (or measuring) them. Ideally, the endpoint should be in terms of human health, since that is what society values. ${ }^{7}$ However, these data are frequently not available, and in some circumstances other indicators are adequate. Phillips and others define the following sequence of effects for vector control:5 outputs of goods and services (e.g., houses sprayed, ponds cleaned), outcomes on the vector (e.g., change in abundance and longevity), outcomes on human behavior (e.g., use of bed nets), impacts on disease (e.g., reduction in morbidity and mortality), and impacts on socioeconomic variables (e.g., reduction in treatment costs; return from income-generating activities).

For example, output indicators would be adequate if the prime concern was with operational efficiency and if it was extremely likely that a particular output produced a health status effect.

The choice of indicators of effect is relatively straightforward when control strategies are being compared for one disease. If the comparison is among several diseases, an indicator has to be chosen that adequately reflects the health status consequences of all the diseases. In the developing country literature, favored candidates are discounted healthy years of life ${ }^{8}$ and disability adjusted life years. ${ }^{9}$ These measures represent the gain in healthy years of life provided by an intervention and allow for mortality, morbidity, and disability improvements, and time preference (preferring benefits sooner rather than later).

In relation to benefits, the major problem is how to value intangible benefits. The approach commonly recommended for developed country studies is to assess people's willingness to pay. ${ }^{10}$ While theoretically attractive in some respects, this has the drawback that estimates would reflect ability to pay (and thus the distribution of income), and that estimates are extremely difficult to make because on the whole people do not pay and thus there are few values to observe. In the absence of better measures, studies in developing countries have used the human capital approach. This treats health expenditure as an investment in people that enables them to be more productive. The main benefits of improved health are increased production. This approach, although much used in the past (see below), is disliked by many economists since it implies that we value people purely as producers, which is patently not the case." Nonetheless, increased production is an important component of benefits, but can be included in cost-effectiveness analysis along with measures of health effect.

Two further points are important when the components of the analysis are being put together. First, when costs and effects/benefits are being analyzed over time, a discount rate is applied to allow for time preference: the fact that people prefer benefits sooner rather than later. In vector control studies, the choice of the level of discount rate can be important since the higher the rate, the more heavily are future costs and benefits discounted. Cohn demonstrated that the level of discount rate would have affected the choice between malaria eradication and control in India, ${ }^{12}$ and Little also found that the level of discount rate would affect the choice of means to eradicate yellow fever in South America. ${ }^{13}$

Second, cost-effectiveness analysis calculates an average cost and is indifferent to the scale of effects. However, the average cost may change with the size of the project. The cost would decrease if there are economies of scale (the larger the scale of activity, the lower the unit cost), as has been demonstrated for source reduction for salt marsh mosquito abatement in the United States. ${ }^{14}$ It would increase if infected individuals are harder to locate. Thus, different project sizes may need to be evaluated. Also, the option with the lowest cost per unit of health effect may have fewer health effects than an alternative. In these circumstances, incremental analysis is important, i.e., calculating the additional cost of achieving additional effectiveness. 
THE EVOLUTION OF STUDIES ON THE ECONOMICS OF VECTOR CONTROL STRATEGIES FOR CONTROLLING TROPICAL DISEASES

The application of economics to vector-borne disease has a long history. The initial concerns of analysts were commercial: "It is the purpose of the Department of Agriculture to place the prevention of malaria on the farm upon a business basis. It remains to show what malaria means to a cotton planter in so many dollars and cents." 15 This focus was not confined to the United States: a classic study of what malaria costs India stated that "Malaria. . ...is an infection that does not kill at the first attack, except in the most malignant type. It is, however, the recurrent attacks in the untreated and partially treated cases that sap the vitality of the masses, undermine their constitution, reduce their physical stamina and create in them a state of chronic debility that prevents the full economic value of the peasantry and industrial workers. Productivity of the soil thus becomes greatly reduced, and economic distress, poverty, disease and death follow in its wake." 16

This sets the context for the economic analyses of vector-borne diseases up to the 1970s. Studies were of two main types: those that attempted to quantify the cost of disease, i.e., its impact in terms of costs of treatment and prevention, and loss of production, and those that assessed the contribution of vector control to raising per capita income through a cost-benefit analysis that compared control (eradication) costs with saved expenditure on prevention and treatment and production gains. Two different types of criticism can be leveled at these studies. The first concerns their lack of empirical foundation. The standard approach was to take an estimate of the total cases of the disease affecting productive age groups and multiply this by the average number of days ill per case and by some value of a day's work to obtain a total value for production lost. This approach has many obvious deficiencies, not the least of which is the often unrealistic estimates of days lost (e.g., 44 days per case of malaria per year reported by Ortiz $^{17}$ ), and assumptions that days lost equals production lost, which equals production gained if control were to be achieved. Only a few studies have carefully investigated the relationship between disease and productivity (e.g., Weisbrod and others, ${ }^{18}$ Conly, ${ }^{19}$ Audi- bert, ${ }^{20}$ and Bhombore and others; ${ }^{21}$ none of these attempted a cost-benefit analysis), and the relationship is by no means proven, in no small part because of its complicated nature and the way in which many households adapt to cope with ill health (e.g, by reallocating responsibilities for productive activities among family members and reducing leisure time).

The second main criticism of these studies concerns their relevance to policy decisions. In the case of the cost-of-disease studies, knowing the magnitude of the loss is not much help to policy makers; what matters is whether something can be done about the disease at an affordable cost. Moreover, the cost of lost production is an imperfect reflection of the true burden of the disease because it ignores any impact on nonproducers such as the elderly and children. A similar criticism can be leveled at the costbenefit analyses since these studies used the same human capital approach and ignored other, less tangible benefits of disease control. For example, Cohn concluded in relation to India that because malaria control would not only increase production but also raise population growth, "the economic case for malaria control may not be very strong"'.22 This wrongly implies that there are economic objectives and humanitarian objectives, and that economic analysis is indifferent to the latter. As stated earlier, economics is concerned with the contribution of projects to all social objectives, which are likely to include improving health and not just raising per capita income.

Despite these shortcomings, policy makers still call for studies of the economic impact of particular diseases, ${ }^{23}$ in the hope that national development authorities will thereby be persuaded of the virtues of investing in health. However, the technique of greatest value to program managers is cost-effectiveness analysis. It avoids the problem of pretending to value all benefits, and in addition can address the question of operational efficiency, which should be of concern to all managers. In recent years, interest in cost and cost-effectiveness analyses in other parts of the health sector, e.g., primary health care, ${ }^{24} \mathrm{im}$ munization programs, ${ }^{25}$ and diarrheal diseases, ${ }^{26}$ has grown considerably. With the exception of the efforts of the Panel of Experts on Environmental Management for Vector Control $(\mathrm{PEEM})^{27}$ and a few researchers, little attention seems to have been paid to using economic anal- 
TABLE 1

Studies illustrating different choices and analytical techniques

\begin{tabular}{|c|c|c|}
\hline Alternatives & Analytical approach & Investigators \\
\hline None & $\begin{array}{l}\text { Cost analysis } \\
\text { Outcome analysis } \\
\text { Cost-benefit analysis }\end{array}$ & $\begin{array}{l}\text { Chu and others } \\
\text { Rajagopalan and Panicker } \\
\text { Schofield and Dias } \\
\text { 36 }\end{array}$ \\
\hline Within vector control & Cost analysis & $\begin{array}{l}\text { Phillips and Mills }{ }^{37} \\
\text { Gandahusada and others }\end{array}$ \\
\hline $\begin{array}{l}\text { Vector control versus other control } \\
\text { methods for same disease }\end{array}$ & $\begin{array}{l}\text { Cost analysis } \\
\text { Cost-effectiveness analysis }\end{array}$ & $\begin{array}{l}\text { Jordan }{ }^{40} \\
\text { Rosenfield and others }{ }^{41} \\
\text { Shaw }\end{array}$ \\
\hline $\begin{array}{l}\text { Vector control versus other inter- } \\
\text { ventions for different diseases }\end{array}$ & Cost-effectiveness analysis & $\begin{array}{l}\text { Prost and Prescott }{ }^{42} \\
\text { Jamison and others }\end{array}$ \\
\hline
\end{tabular}

ysis to improve the efficiency of vector control operations in developing countries.

THE CURRENT USE OF ECONOMIC ANALYSIS TO ANALYZE VECTOR CONTROL STRATEGIES

In the space of this paper, it is not possible to give a complete description of all the studies that have used economic analysis to help identify efficient vector control strategies. Instead, to indicate the sort of studies that can be done and the assistance they can provide to decision-makers, five different types of choices concerning vector control are identified, and illustrative studies that have explored these choices are discussed. The choices, analytic approaches, and studies are shown in Table 1 . These studies are not intended to be representative of the whole literature, but have been chosen to indicate the usefulness of empirical studies focusing on particular questions of local relevance. Readers wishing more comprehensive reviews for particular diseases can consult the individual chapters in Jamison and others ${ }^{9}$ (particularly those on malaria, ${ }^{28}$ dengue, ${ }^{29}$ and helminth infection ${ }^{30}$ ), Ngare and Lamounier on onchocerciasis, ${ }^{31}$ and Barlow and Grobar $^{32}$ for a comprehensive review of economic evaluation studies relating to parasitic disease control.

The essential features of economic evaluation are 1) the comparison of the additional costs and consequences following from implementing an intervention, and 2) the comparison of the costs and consequences of alternative interventions. That said, there are many studies that do not make either type of comparison, and many others that do one but not the other. ${ }^{33}$ Although partial analyses, ${ }^{10}$ they can still provide some useful information. For example, Chu and others calculated the annual cost of cercarial transmission control in the Volta Lake in Ghana, including the combined cost of molluscicides, weed removal, and chemotherapy. ${ }^{34}$ Information was collected on prevalence changes, but a cost-effectiveness ratio was not calculated and since no alternative control measures were evaluated, it is not possible to tell whether any different mix of strategies would be less costly or more effective. However, the study does give an idea on the vital issue of affordability and whether such control measures could be sustained.

Rajagopolan and Panicker presented another partial analysis that focused on describing the consequences of vector control. ${ }^{35}$ They quantified the direct socioeconomic benefits of mosquito control activities in a coastal village in Pondicherry, India. Activities included economic exploitation of algae and prawn culture, both of which contributed to mosquito control and also generated income. Although the income from the schemes is stated, it is not clear whether this is pure profit or whether production costs should be deducted. However, the study highlights an important category of benefit that is particularly relevant to environmental management strategies.

Schofield and Dias assessed the value of preventing Chagas' disease by comparing control costs (of house spraying) only with saved medical care costs and avoidance of the cost of funerals for deaths occurring in the acute phase. ${ }^{36}$ They term the study a cost-benefit analysis, although it is a partial one since it does not quantify other benefits. Their justification is that control is evidently worthwhile even on the basis of 
their limited consideration of benefits. However, their treatment costs saved are hypothetical, as they admit, in that they assume that everyone who requires care would get it. Moreover, they assume that their estimated costs of medical care reflect the value, in their alternative use, of the resources saved when, for example, fewer pacemakers or less corrective digestive surgery are required. The existing average costs of treatment do not necessarily represent the resources saved (e.g., some resources may be used also by other services and may not be released); also, not all the resources released may be productively used.

The general approach of this study, to compare costs of prevention with saved treatment costs, can indicate worthwhile interventions. However, two caveats are necessary: first, even if an intervention is not justified by reference to saved treatment costs, it does not necessarily follow that it is not worth implementing, since health improvement is valued for its own sake. Second, the poorer the country (or geographic area within the country), the less extensive will be the health infrastructure and thus the smaller the potential savings. Thus, an analytical approach that focuses on efficiency improvements can contradict distributional objectives to improve the position of the worst-off that would give high priority to poorer or poorest areas.

The comparison of strategies within vector control is ideally suited to cost-analysis and cost-effectiveness analysis because the various strategies tend to have a number of endpoints in common, and useful conclusions can be derived without necessarily having information on health effects. Phillips and Mills, for example, compared the costs of spraying three insecticides, DDT, Malathion and Ficam (bendiocarb), concentrating particularly on the costs of delivering the insecticides to house walls, since these are costs often ignored by researchers but are frequently paid locally (rather than by donors). ${ }^{37}$ Although DDT was by far the cheapest per house sprayed, and also had the lowest noninsecticide costs, the choice of chemical in Nepal depended primarily on donor preference, a common constraint in achieving economic efficiency. Gandahusada and others analyzed costs for fenitrothion spraying only, but compared two cycles of full coverage and one of selective coverage with three cycles of selective coverage. ${ }^{38}$ Data on epidemiologic endpoints were collected and cost-effectiveness ratios could have been calculated, although the study computed only cost per person protected. Both strategies reduced malaria rates and vector populations to very low levels (although full coverage achieved this reduction more quickly), but selective treatment was $68 \%$ cheaper than full coverage. As more expensive insecticides are used, the insecticide share of the total cost tends to be greater, as does the potential savings from more selective coverage. ${ }^{39}$

When the strategy of vector control is being compared with alternative strategies of prevention or treatment for the same disease, cost analysis tends to be less useful than cost-effectiveness analysis because the strategies compared may have different effects. Jordan reported the results of a comparative evaluation of snail control, chemotherapy and provision of water supplies for schistosomiasis control in St Lucia. ${ }^{40}$ Annual costs per capita, rather than cost-effectiveness ratios, were calculated, and were lowest for chemotherapy, followed by snail control and water supplies. Epidemiologic data showed that chemotherapy was the procedure most rapidly effective, and also provided treatment benefits. A subsequent calculation of cost per case year averted confirmed the ranking of the interventions, ${ }^{32}$ so in this instance, cost analysis alone was not misleading. However, this study indicates one of the classic problems of cost-effectiveness analysis: finding an indicator of effectiveness that adequately reflects all the consequences of the alternatives. In this study, cases prevented is clearly only a partial measure of the consequences of water supplies; they are evaluated only in terms of their contribution to schistosomiasis control, and other social benefits are ignored.

A classic cost-effectiveness study of alternative strategies for schistosomiasis control used decrease in prevalence at the end of seven years of control and case years of infection prevented as indicators of effectiveness. ${ }^{41}$ The main interest of this study is that a transmission model was used to model the impact of control alternatives. This not only makes it relatively easy to explore the implications of alternative values for the variables in the model (termed sensitivity analysis), but also facilitates handling the comparison of alternative mixes and timing of strategies. A modeling approach was also adopted in a comparison of vector control and case finding and treatment for human trypanosomiasis. ${ }^{4}$ The 
study is of particular interest because it tackles a problem common to comparisons of vector control and treatment: how to define the unit of effect when one strategy prevents disease and the other treats. The study describes itself as analyzing costs and benefits, but since the benefit unit is defined as the prevention of one year of infection (so the stream of benefits over time is the difference between prevalence with control and without control), it is more appropriately described as a cost-effectiveness study. In this case, the model is a very simple one, confined to analyzing the relationships between costs and effects. However, the paper is unusual in discussing cost determinants, and demonstrates how a spreadsheet model can help to identify the most important variables.

The comparison of interventions against very different diseases is of less relevance to a vector control program manager, but of importance to national decision-makers who need to set priorities. Prost and Prescott, having estimated the cost-effectiveness of blindness prevention by the Onchocerciasis Control Programme in terms of healthy years of life gained, made an illustrative comparison with the cost-effectiveness of measles immunization. ${ }^{42}$ They found that the relative attractiveness of blindness prevention depended on the effectiveness measure: the measure of discounted productive years of healthy life gained favored blindness prevention, whereas undiscounted measures and including all years of life favored measles immunization. This emphasizes the importance of careful choice of effectiveness measure and of explicit discussion of the values inherent in the measure used. A much more extensive comparison of disease control priorities has been undertaken by Jamison and others. ${ }^{9}$ They rank measures to improve child health and adult health (including vector control) in terms of the cost per disability adjusted life year gained. As they state, such a ranking can only illustrate the potential cost-effectiveness of alternative interventions: actual cost-effectiveness can vary enormously between countries depending on a variety of local circumstances. Thus, the relevance of their conclusions must be checked at the country level by those countries wishing to apply the same approach to priority setting.

Although all of the above studies help to shed some light on the choices in vector control and on methods of analysis, this brief review high- lights some important methodologic concerns. First, many studies do not bother to compare alternatives, although little can be concluded on the basis of a single-cost per capita or cost-perhealth effect. Second, studies done by economists tend to lack good epidemiologic data, and studies done by epidemiologists and scientists often lack good cost data; indeed, cost-effectiveness ratios may not be calculated even when the data are available to do so. Third, excessive attention is given to quoting cost per capita measures. These can be quite misleading, since the denominator will include people receiving no benefit (those with natural immunity, those living in pockets of zero transmission, those who fall ill despite the control activities, those who were infected prior to the control project). ${ }^{32} \mathrm{Fi}$ nally, it is evident that the levels of transmission of vector-borne diseases can vary considerably from one area to another, even within a country, to the extent that the choice of control strategies may be different in different locations. Thus, analysts should include in their studies consideration of the factors that may influence cost-effectiveness so that the applicability of the conclusions elsewhere can be considered.

The fact that useful policy implications can be drawn, as indicated in the above review, from imperfect studies is not an excuse for poor analytic approaches. However, methodologic purity and perfect data should not be sought for their own sake. For some policy and planning issues, crude data may be sufficient to provide a clear answer; for others, a carefully designed study may have to be set up. It is incumbent on the analyst to judge the level of effort necessary to provide an answer; indeed, to apply the principles of cost-effectiveness analysis to his or her own activities!

\section{THE OUTLOOK FOR THE FUTURE}

Several reviews of economic evaluation literature relevant to vector control strategies for controlling tropical diseases have concluded that we do not yet know enough to provide clear advice on choice of control strategy. For example, Barlow and Grobar identified three main conclusions from their very extensive review of parasitic disease control: ${ }^{32}$ 1) there are substantial gaps in knowledge about cost-effectiveness and cost-benefit ratios, 2) there appear to be big differences in the cost-effectiveness of alternative 
means of control, and 3) the cost-effectiveness of a given control strategy can vary widely from location to location.

To these, Kaewsonthi adds the concern that knowledge of costs and effectiveness do not by themselves produce changes in organizations, especially where there are long established practices. ${ }^{43}$

It is clear that spraying is costly and often ineffective," and that community participation and environmental management have the potential to control certain vectors in certain circumstances at low cost. ${ }^{44}$ However, more studies are needed before useful conclusions can be drawn that will help program managers decide which vector control strategies or mix of strategies are most cost-effective.

The outlook for the future would be much improved if the following methodologic guidance was followed: 1) whenever possible and relevant, research on control strategies should have both epidemiologic and economic components, 2) more attention should be paid to producing good quality cost data and also to considering the determinants of cost and effectiveness in a particular site so that the relevance of the findings to other locations can be considered, and 3 ) computer models can be used successfully to manipulate the variables in the analysis and undertake sensitivity analysis.

In terms of research priorities, cost-effectiveness analysis of routine control activities, which involves the control staff so that they are encouraged to implement changes, is obviously important to improve efficiency. So is including an economic component in the evaluation of new control technologies to check that they are not only effective but also cost-effective. There appears to be a strong demand from policy makers for information on the impact of disease on production. There is some scope for more sophisticated econometric modeling, but it is also important to use qualitative techniques to explore in depth how households cope with illness and disability; 45 these will help to develop hypotheses that can later be tested using more quantitative approaches.

Acknowledgment: The author is head of the Health Economics and Financing Programme at the London School of Hygiene and Tropical Medicine, which is supported by the United Kingdom Overseas Development Administration.

Author's address: Anne Mills, Health Policy Unit, De- partment of Public Health and Policy, London School of Hygiene and Tropical Medicine, Keppel Street, London WC1 7HT, United Kingdom.

\section{REFERENCES}

1. Mishan EJ, 1982. Cost-Benefit Analysis. London: George Allen and Unwin.

2. Squire L, van der Tak HG, 1975. Economic Analysis of Projects. Baltimore and London: Johns Hopkins University Press.

3. Mills A, Drummond M, 1987. Value for money in the health sector: the contribution of primary health care. Health Policy Planning 2: 107128.

4. Shaw APM, 1989. Comparative analysis of the costs and benefits of alternative disease control strategies: vector control versus human case finding and treatment. Ann Soc Belg Med Trop 69 (suppl 1): 237-253.

5. Phillips M, Mills A, Dye C, 1993. Guidelines for Cost-Effectiveness Analysis of Vector Control. Geneva: Panel of Experts on Environmental Management for Vector Control (in press).

6. Tameim O, Zakaria, ZB, Hussein H, El Gaddal AA, Jobin WR, 1985. Control of schistosomiasis in the new Rahad Irrigation Scheme of Central Sudan. J Trop Med Hyg 88: 115-124.

7. Mills AJ, Bradley DJ, 1987. Methods to assess and evaluate cost-effectiveness in vector control projects. Selected Working Papers Prepared for the 3rd, 4th, 5th and 6th Meeting of the WHO/FAO/UNEP Panel of Experts on Environmental Management for Vector Control. Geneva: PEEM Secretariat, WHO.

8. Barnum H, 1987. Evaluating healthy days of life gained from health projects. Soc Sci Med 24: 833-841.

9. Jamison DT, Mosley WH, Measham AR, Bobadilla J-L, eds, 1993. Disease Control Priorities in Developing Countries. New York: Oxford University Press for The World Bank (in press).

10. Drummond MF, Stoddart GL, Torrance GW, 1987. Methods of Economic Evaluation of Health Care Programmes. Oxford: Oxford University Press.

11. Mills A, 1991. The economics of malaria control. Targett GAT, ed. Malaria: Waiting for the Vaccine. Chichester: John Wiley and Sons.

12. Cohn EJ, 1973. Assessing the costs and benefits of anti-malaria programs: the Indian experience. Am J Public Health 63: 1086-1096.

13. Little AD, 1972. The Prevention of Diseases Transmitted by Aedes aegypti in the Americas: a Cost-Benefit Study. Washington DC: Pan American Health Organization.

14. DeBord DV, Carlson GA, Axtell RC, 1975. Demand for and Cost of Coastal Salt Marsh Mosquito Abatement. Raleigh, NC: North Carolina Agricultural Experiment Station Technical Bulletin No. 232.

15. Herrick GW, 1903. The relation of malaria to agriculture and other industries of the south. Popular Sci Monthly (April): 521-525. 
16. Sinton JA, 1935. What malaria cost India, nationally, socially and economically. Rec Malaria Survey India 5: 223-264.

17. Ortiz JO, 1968. Estimacion del costo de un programa de erradicacion del paludismo. Bol Oficina Sanit Panam 64: 110-115.

18. Weisbrod BA, Andreano RL, Baldwin RE, Epstein $\mathrm{E}$, Kelley AC, with the assistance of Helminiak TW, 1973. Disease and Economic Development. The Impact of Parasitic Diseases in St. Lucia. Madison, WI: University of Wisconsin Press.

19. Conly GN, 1975. The Impact of Malaria on Economic Development: A Case-Study. Washington, DC: Pan American Health Organization, Scientific Publication No. 297.

20. Audibert M, 1986. Agricultural non-wage production and health status: a case-study in a tropical environment. J Dev Econ 24: 275-291.

21. Bhombore SR, Brooke Worth C, Nanjundiah KS, 1952. A survey of the economic status of villagers in a malarious irrigated tract in Mysore State, India, before and after DDT residual spraying. Indian J Malariol 6: 355-366.

22. Cohn EJ, 1972. Assessment of malaria eradication costs and benefits. Am J Trop Med Hyg 21: 663-667.

23. Lennox RW, 1991. Malaria in Africa: the need for economic analysis. Trop Med Parasitol 42 (suppl 1): 198.

24. Creese A, Parker D, 1990. Cost Analysis in Primary Health Care. Geneva: World Health Organization.

25. Creese AL, Sriyabbaya N, Casabal G, Wiseo G, 1982. Cost-effectiveness appraisal of immunization programmes. Bull World Health Organ 60: 621-632.

26. Programme for Control of Diarrhoeal Diseases, 1988. Estimating Costs for Cost-Effectiveness Analysis. Geneva: World Health Organization.

27. PEEM (Panel of Experts on Environmental Management for Vector Control), 1986. Report of the Sixth Meeting. Part 1. Technical Discussion - Financial and Economic Aspects of Environmental Management, and its Cost-Effectiveness as a Control Measure. Geneva: PEEM Secretariat.

28. Najera J, Liese B, Hammer J, 1993. Malaria. Jamison DT, Mosley WH, Measham AR, Bobadilla J-L, eds, 1993. Disease Control Priorities in Developing Countries. New York: Oxford University Press for The World Bank.

29. Shepard D, Halstead S, 1993. Dengue. Jamison DT, Mosley WH, Measham AR, Bobadilla J-L, eds, 1993. Disease Control Priorities in Developing Countries. New York: Oxford University Press for The World Bank.

30. Warren K, Bundy D. Anderson R, Davis AR, Henderson DA, Jamison JT, Prescott N, Serft A, 1993. Helminth infections. Jamison DT, Mosley WH, Measham AR, Bobadilla J-L, eds. Disease
Control Priorities in Developing Countries. New York: Oxford University Press for The World Bank.

31. Ngare DK, Lamounier J, 1989. Onchocerciasis. The World Bank Health Sector Priorities Review. Washington DC: The World Bank.

32. Barlow R, Grobar LM, 1985. Costs and Benefits of Controlling Parasitic Diseases. PHN Technical Note 85-17. Washington, DC: Population, Health and Nutrition Department, The World Bank.

33. Mills, A, 1985. Survey and examples of economic evaluation of health programmes in developing countries. World Health Stat $Q$ 38: 402-431.

34. Chu KY, Klumpp RK, Kofi DY, 1981. Results of three years of cercarial transmission control in the Volta Lake. Bull World Health Organ 59: 549-554.

35. Rajagopalan PK, Panicker KN, 1985. Financial rewards ensure community involvement. World Health Forum 6: 174-176.

36. Schofield CJ, Dias JCP, 1991. A cost-benefit analysis of Chagas disease control. Mem Inst Oswaldo Cruz 86: 285-295.

37. Phillips M, Mills A, 1991. The operational cost of insecticide spraying for malaria control: a case-study from Nepal. J Trop Med Hyg 94: $130-139$.

38. Ganduhusada S, Fleming GA, Sukamto, Damar T, Suwarto, Sustriayu N, Bang YH, Arwati S, Arif H, 1984. Malaria control with residual fenithrothion in Central Java, Indonesia: an operational-scale trial using both full and selective coverage treatments. Bull World Health Organ 62: 783-794.

39. Mills AJ, 1992. Economic evaluation of disease control technologies: the case of malaria control in Nepal. Soc Sci Med 34: 965-972.

40. Jordan $P, 1977$. Schistosomiasis: research to control. Am J Trop Med Hyg 26: 877-886.

41. Rosenfield PL, Smith RA, Wolman MG, 1977. Development and verification of a schistosomiasis transmission model. Am J Trop Med Hyg 26: 505-516.

42. Prost A, Prescott N, 1984. Cost-effectiveness of blindness prevention by the Onchocerciasis Control Programme in Upper Volta. Bull World Health Organ 62: 795-802.

43. Kaewsonthi S, 1991. The economics of malaria control: workshop report and recommendations. Targett GAT, ed. Malaria: Waiting for the Vaccine. Chichester: John Wiley and Sons, 165168.

44. Gubler D, 1989. Aedes aegypti and Aedes aegypti-borne disease control in the 1990s: top down or bottom up. Am J Trop Med Hyg 40: 571578.

45. Watts SJ, Brieger, WR Yacoob, M, 1989. Guinea worm: an in-depth study of what happens to mothers, families and communities. Soc Sci Med 29: 1043-1049. 